\title{
El reto de envejecer: la vejez a la luz de Flannery O'Connor, Erik Erikson y Romano Guardini
}

\author{
SUSANA MIRÓ LÓPEZ* \\ Universidad Francisco de Vitoria (España) \\ s.miro@ufv.es \\ FERNANDO VIÑADO OTEO** \\ Universidad Francisco de Vitoria (España) \\ f.vinado@ufv.es
}

\begin{abstract}
Resumen
El siguiente estudio pretende concienciar a la sociedad sobre la problemática de los mayores en nuestros días. La esperanza de vida aumenta en los países desarrollados, pero nuestro mundo parece considerar a los ancianos como personas no útiles para el entramado social. Analizaremos dos relatos de la autora americana Flannery O'Connor -El geranio y El día del Juicio Final- en los que sus protagonistas son mayores. Las conclusiones serán enriquecidas a la luz de las teorías psicosociales del alemán Erik Erikson y del planteamiento sobre las etapas de la vida del también alemán, el filósofo Romano Guardini. Tres figuras de distintas áreas del saber que ya advirtieron de la deriva social a la que se verían abocados nuestros mayores si no se cambiaba de mentalidad y se tomaban medidas.
\end{abstract}

Palabras clave: Flannery O'Connor, Erik Erikson, Romano Guardini, personas mayores, dignidad.

\section{The challenge of aging: old age in the light of Flannery $O^{\prime} C o n n o r$, Erik Erikson and Romano Guardini}

\begin{abstract}
This article intention is to raise awareness in society in relation to the problem of the elderly in today's world. Life expectancy is increasing in developed countries; however, old people are being considered useless or even a burden to be eliminated in modern society. We will analyse two stories from the north American author Flannery O'Connor called -The Geranium and Judgement Day-which have old people as their main characters. The conclusions will be enlightened by the psychosocial theories from Erik Erikson and by the German philosopher Romano Giardini's approach on the different phases in life. Three wise authors coming from different perspectives which already warned of the social drift that our elders would be doomed unless we change our mentality and take immediate measures.
\end{abstract}

Key words: Flannery O'Connor, Erik Erikson, Romano Guardini, older people, dignity.

Doctora en Humanidades y Ciencias Sociales por la Universidad Francisco de Vitoria, donde es docente en el Departamento de Formación Humanística. Entre sus publicaciones recientes: El misterio del sufrimiento en la obra de Flannery O'Connor a la luz de Romano Guardini: La presencia silenciosa de Dios (2020).

** Doctor en Educación por la Universidad Complutense de Madrid. Vicerrector de Formación Integral y profesor de Humanidades en la Universidad Francisco de Vitoria. Entre sus publicaciones recientes: Formar a los docentes de Educación Infantily Primaria desde un magisterio centrado en la persona (2019).

Recibido: 16/Abril/2020 - Aceptado: 24/Septiembre/2020 


\section{PlanteAmiEnTOS INTRODUCTORIOS}

La obra literaria de la escritora sureña Flannery O'Connor (19251964) está compuesta de treinta y dos relatos cortos y dos novelas; además nos dejó una serie de ensayos, conferencias, reseñas y centenares de cartas que nos permiten adentrarnos en la personalidad de O'Connor. En su narrativa, nos encontramos con un variado elenco de personajes grotescos que muestran las debilidades del ser humano tanto desde el punto de vista físico como moral. De ahí quizás que sus obras no tuvieran tanta divulgación. Al lector no siempre le agrada el tono provocador de sus relatos y menos sentirse interpelado e incluso identificado por los protagonistas de sus novelas y relatos. Pero este mismo hecho, ha posibilitado que su obra se universalice y podamos considerarla una de las literatas americanas más reconocidas del siglo XX (Scott \& Streight, 2009: 73). Su obra se desarrolla en un momento en que el Sur comienza a despegar literariamente hablando, se forjan los cimientos del gran "renacimiento" sureño, es en este movimiento donde situamos a O'Connor. Según Manuel Broncano, el periodo que se extiende desde el inicio de la Gran Depresión hasta el final de la Segunda Guerra Mundial es el tiempo más prolífico de toda la historia del género narrativo en América (1992: 38). William Faulkner (1897-1962) es la figura central de este "renacimiento del Sur", sus títulos The Sound and the Fury y Intruder in the Dust son obras claves de este momento. Se incluyen autores como Thomas Wolfe (1900-1938), Tennessee Williams (19111983), Peter Taylor (1917-1994), Robert Penn Warren (1905-1989) y las conocidas como "ladies of the South", donde resaltan literatas de la talla de Caroline Gordon (1895-1981), Catherine Anne Porter (1890-1980), Eudora Welty (1909-2001), Carson MacCullers (1897-1967) y la propia Flannery, que forma parte de una segunda generación en la que estarían escritores como Truman Capote (1924-1984) y William Styron (1925-2006).

Este movimiento surge por el temor de las personas del Sur a perder su propia identidad. Una sociedad eminentemente agraria que se encuentra amenazada ante la industrialización norteña y que ve con recelo la nueva base económica que parece ha venido para quedarse y liderar una nueva época. Estos literatos pretenden rescatar lo bueno de la tradición sureña recuperando las señas de identidad más valiosas del espíritu de sus gentes. O'Connor mantiene en sus obras los rasgos más característicos de su generación: los ambientes que describe son pinceladas realistas de diferentes regiones sureñas y el lenguaje de sus personajes presenta las variedades idiomáticas del Sur.

Rasgo identitario de la producción flanneriana es que sus cuentos están sembrados de seres humanos imperfectos, muertes, suicidios, crímenes diversos, etc. por paradójico que parezca, con estas figuras pretende 
mostrarnos la grandeza de la vida humana y cómo merece la pena ser vivida. Es más, O'Connor de tradición y formación católica, procura con sus relatos que el lector eleve los ojos hacia otra realidad. Aunque en el mundo existe el mal, en la batalla contra la maldad, el ser humano no está solo: Dios decidió encarnarse para entrar en nuestra realidad y superar así las leyes del dolor, del sufrimiento y de la muerte, y sustituirlas por un mensaje de redención. Así, la propia O’Connor comenta "desde el punto de vista del misterio cristiano central: pese a todo su horror, Dios ha considerado que merecía la pena morir por ella", refiriéndose a la maldad del mundo (2007: 154). La escritora enfrenta a sus personajes a circunstancias dantescas, los lleva a una situación límite en la que pueden reaccionar: se ven necesitados y pueden o no descubrir al Dios que los acompaña, aún más si cabe, en el pecado y en la debilidad.

Como hemos comentado, la literatura de O'Connor no siempre ha sido bien acogida por el público. En una primera lectura, el mensaje de esperanza que destilan sus obras no es fácil de captar. Por ello, parte de la crítica literaria asemeja su estilo a los autores de la corriente "Southern Gothic" (Álvarez, 1992: 417) que surge en la década de los años veinte y se refiere a toda la ficción procedente del Sur que presenta un panorama sumamente pesimista. Sus orígenes se remontan a la literatura americana conocida como "corriente oscurantista" que lidera Allan Poe (1809-1849). De ahí que Lancelotti comparara la obra de la sureña con la del americano y llega a ver un cierto paralelismo con la de Kafka (1965: 38). Sin embargo, la propia O'Connor comenta que sus cuentos no pretenden ser un reflejo de la obra de Poe, aunque no niega que Humerous Tales le había marcado a la hora de comenzar su aventura como escritora. Si bien Flannery insiste en que, la aparente dureza de sus cuentos revela la profundidad del misterio central de toda su obra: todo lo grotesco y el pecado del mundo se redime por Cristo que ofrece su mano amorosa al hombre para que este, en el uso de su libertad, lo acoja (2007: 133). Su obra, lejos de pertenecer a este movimiento gótico, se sitúa en un modo narrativo grotesco (Broncano, 1992: 18-22). Este modo grotesco de narrar las situaciones y los ambientes pretenden reflejar el misterio de la propia existencia del ser humano, el desconcierto de lo cotidiano ante la gran incógnita que revela la transcendencia. La narrativa de la autora nos sitúa en un nivel más allá del realismo social del momento, nos sitúa en un verdadero plano metafísico. Guadalupe Arbona identifica esta superación de lo cotidiano para acercar al lector a la naturaleza del misterio con autores como Conrad (1857-1924) o Henry James (1843-1916), esta apertura al significado profundo de las obras lo definiría como "realismo de distancias" (2006: 20). 
Dentro de la obra de O'Connor, hemos querido centrarnos en dos de sus cuentos, El geranio y El día del Juicio Final, en los que describe una sociedad que se olvida de sus mayores y cómo la soledad es vivida de forma diferente por cada uno de los protagonistas. O'Connor, como en tantos momentos de su obra, está anticipando una circunstancia, que por dura que parezca, se ha convertido en algo muy habitual en nuestros días. Su crítica mordaz a través de sus relatos nos cuestiona a nosotros como sociedad: vivimos en un mundo vertiginoso, con unas estructuras que valoran a las personas en función de su utilidad y se olvidan de su dignidad como seres humanos. En un mundo así, los mayores no tienen cabida. Pero ¿qué tipo de mundo hemos construido si nos olvidamos de los débiles, de nuestros mayores?

A la par que la americana publicaba sus obras, otras dos figuras como Erik Erikson y Romano Guardini, uno desde la psicología social y el otro desde la filosofía, daban una voz de alarma en el mismo sentido que la escritora.

Cuando las tropas nazis toman el poder, Erikson, por la ascendencia judía de su familia, huye a Copenhague y desde allí a Estados Unidos. Desarrolla sus conocimientos de psicoanálisis en su consulta y en 1950 publica su obra Childhood and Society. En este libro, incorpora un capítulo sobre su teoría de ocho etapas del desarrollo humano. Esta teoría la irá perfeccionando en publicaciones posteriores, en particular en su obra Identity and the Life Cycle que sale a la luz en 1959. De la teoría de Erikson, nos centraremos para nuestro escrito en la última etapa: desde los 60 años al final de la vida. Y a la luz de su análisis estudiaremos a los dos personajes de los cuentos de O'Connor.

Para completar el estudio, recurriremos a uno de los pensadores que más han influido en O'Connor: Romano Guardini. La propia escritora recomienda a sus amigos y familiares la lectura de su obra. La americana reseña su obra y todas las semblanzas son recogidas en un libro con carácter póstumo que lleva por título: The Presence of Grace and Other Book Reviews by Flannery O'Connor. La admiración que O'Connor siente por Guardini la muestra en sus cartas: "estoy leyendo todo lo que puedo sobre Romano Guardini” (2004: 74). En 1953, publica Die Lebensalter: Ibre ethische und pädagogische Bedeutung, en 1997 la obra se traduce al castellano bajo el título Las etapas de la vida. Su importancia para la ética y la pedagogía. En este libro, Guardini desarrolla la importancia de su teoría del encuentro, así reza el prólogo de la edición español: "Su tema «el encuentro» es central en el pensamiento guardiniano” (Guardini, 2015: 6). Más allá de la psicología o sociología, el autor pretende analizar el sentido de la vida en cada etapa humana. Nos centraremos, de nuevo, en la etapa última de la vida. Guardini habla de tres momentos evolutivos: el hombre sabio, la entrada en la ancianidad y 
la persona senil. En la misma obra se incorpora una charla radiofónica del filósofo titulada: Del Envejecer, que nos servirá para dialogar con los personajes de los dos cuentos flannerianos.

\section{LOS MAYORES: DUDLEY Y TANNER, COMIENZO Y CULMEN LITERARIO DE O'CONNOR}

Dentro de la producción literaria de O'Connor es indiscutible que su tarjeta de presentación son sus relatos. Comienza su carrera literaria precisamente con el relato que nos ocupa: El geranio, escrito en 1946. Pese a ser su primer cuento, goza de los rasgos propios de la sureña: sus argumentos y personajes son realistas, poniendo especial atención en aquellos aspectos más controvertidos de las personas. Y culminará sus escritos con El día del Juicio Final, datado entre 1964-1965. El relato es la versión mejorada formalmente del primero. El deterioro físico de O'Connor era evidente, sus días estaban llegando al final y su obra cierra así también el ciclo.

Nos encontramos con dos personajes: en el primero, el viejo Dudley; en el segundo, el anciano Tanner. El argumento se mantiene en ambos: Dudley, dado su avanzada edad y la precaria situación económica que tiene se muda a vivir con su hija a Nueva York; Tanner, lo mismo. Sin embargo, hay una diferencia entre los dos, una evolución de los personajes y del ambiente social.

Comencemos por Dudley, un hombre angustiado por la soledad infinita a la que se enfrenta al mudarse a la casa de su hija. Paradójico, deja su pueblo para no estar solo y se siente abandonado al trasladarse al hogar familiar. En este relato, O'Connor contrapone la vida en un entorno rural frente al urbano. Dudley añora su tierra, su casa, sus amigos y sus costumbres. En la ciudad, se pierde en el anonimato de los muros grises de los edificios y del frío asfalto. Su hija no sabe cómo integrarle en la vida cotidiana. Incomunicación ente el padre y la hija que le conduce a esa soledad profunda y a un sentimiento de verse aparcado como un mueble viejo que ya no es útil, solo cabe esperar la muerte física porque espiritualmente ya siente que es el final.

La hija no es capaz de llegar al corazón de su padre, la acogida en su casa no ha sido tal, prima el sentido del deber sin más: "Ella cumplía con su deber. No como sus hermanos" (O'Connor, 2006: 21). Dudley se muda a la ciudad pensando que disfrutaría de una nueva vida, rodeado de los suyos (su hija, su yerno y su nieto), donde podría compartir su experiencia y aconsejar al resto, pero la decepción es inmediata, es como aquel geranio que reposa en el alféizar de la casa del vecino para respirar algo de aire y que Dudley contempla cada día. 
Flannery describe la ausencia de relación entre los personajes acompañándolo de un marco descriptivo deshumanizado: "Aquello era un hormiguero" (2006: 21), todas las descripciones refieren a la falta de identidad en la ciudad. Es más, en el relato no se conocen los nombres de los miembros de la familia, sin embargo, si sabemos cómo se llaman sus vecinos y amigos del pueblo. Sentido de comunidad frente al aislamiento. Cuando la familia sale de la casa para comenzar la actividad cotidiana, Dudley no se atreve a salir a la calle, todo le resulta hostil y permanece sentado mirando al viejo geranio.

Entonces, como es característico de la obra de la escritora, surge la oportunidad que se presenta en todos sus cuentos para revertir la situación: el acontecimiento. Manuel Broncano analizando la obra literaria de O'Connor define este rasgo presente en la narrativa de la sureña como: "un acontecimiento implica la existencia de unos personajes que realizan unas acciones dentro de un marco espacio-temporal determinado, fruto de las cuales se produce una transformación reconocible de alguno de los factores que intervienen en el mismo" (1992: 77). En El geranio, el acontecimiento se produce de la mano de un nuevo personaje: el vecino negro de la hija. Dudley se ha educado en un momento y lugar donde la convivencia entre blancos y negros es todavía un tanto difícil: los negros ya no eran esclavos, pero eran criados; vivían en las casas de los blancos, pero porque les servían. Es curioso que, pese a esta concepción propia de muchas áreas de los estados sureños, Dudley tenga una relación más íntima con Rabie y Lutisha, el matrimonio de negros que viven en el sótano de su casa, que con su familia de sangre. Cuando ve al vecino negro, no entiende que no fuera un criado y que, sin serlo, viva en el mismo edificio que su hija. El mundo estaba cambiando a una velocidad que él no lo comprende. Este cerrarse a los nuevos tiempos, le va a llevar a desaprovechar la oportunidad que le brinda el relato: aquel negro es la única persona de la ciudad que ha sabido mirar de una forma amable a Dudley. En una de las ocasiones que se cae subiendo las escaleras, el negro le ofrece su ayuda: "Le tendió la mano para que pudiera agarrarse y levantarse" (O' Connor, 2006: 29). Le acompaña y le lleva a su casa. Dudley permanece callado, sin dar crédito al episodio: aquel ser se dirigía a él como si fuera un igual; era inadmisible.

$\mathrm{Y}$, entonces, el desenlace de la historia: Dudley se asoma a la ventana y mira hacia el geranio, no está y la maceta yace hecha añicos en el suelo. Piensa en ir a recogerlo, pero: "No podía bajar y arriesgarse a que los negros le dieran palmadas en la espalda. Volvió al cuarto y a la ventana, se asomó y, allá abajo, vio al geranio" (O’Connor, 2006: 33).

$\mathrm{El}$ inmovilismo del personaje provoca la ausencia total de esperanza. Podía haber dado una oportunidad a aquel vecino, de él dependía, pero no 
quiso. Ahora no cabe más que esperar sentado; la siguiente víctima sería él.

O'Connor en este cuento refleja un hecho que se estaba produciendo en los Estados Unidos. La sociedad americana se caracterizaba por contar con una población dedicada mayoritariamente al sector primario, de hecho, durante la etapa colonial el 90\% de la población dependía de la agricultura y vivía en el medio rural. Esta situación continúa durante el siglo XIX hasta las primeras décadas del siglo XX. En los años 20 la crisis agraria, de modo acentuado en los Estados del Norte, provoca el éxodo del campo a las ciudades, sobre todo a Nueva York (Sagredo Santos, t.y.: 75). La hija de nuestro protagonista pertenece a este grupo de ciudadanos que abandona la actividad rural para buscar nuevos empleos en el área urbana. Esta salida generacional, ocasiona situaciones como las que relata la sureña: los mayores se quedan solos. Cuando se enviuda o surgen enfermedades graves que les impiden valerse por ellos mismos, necesitan del otro y de ahí que dejen su entorno rural para mudarse con sus hijos a los núcleos urbanos. No es extraño que suceda entonces lo que el cuento describe.

El conflicto generacional entre el padre y la hija no es solo por la edad, si no por una mentalidad diferente: el padre arraigado a las categorías sureñas y una hija que ya se ha imbuido de un ambiente norteño y urbano. $\mathrm{Ni}$ uno ni otro saben buscar un ámbito de relación que les permita crecer como familia, van a vivir bajo el mismo techo, pero totalmente aislados e incomunicados. Dudley intenta suplir la ausencia de relación con la contemplación de un geranio: el hombre necesitado de Belleza se conforma con la contemplación de una planta que le evoca el recuerdo de sus tierras. Podría haber forjado una nueva amistad con el vecino, pero se cierra a ella por sus prejuicios. Cuando el geranio muere, Dudley comprende que ha perdido incluso la posibilidad del recuerdo agradable y, entonces, rompe a llorar amargamente.

Dejemos el primer relato, lo retomaremos después a la luz de las teorías de Erikson y Guardini, pero vayamos a comparar este relato con El día del Juicio Final. Veremos la evolución en los personajes y el nuevo marco espacio-temporal en el que se desarrolla la historia.

El protagonista de la historia se llama Tanner, el cambio de nombre nos predispone ya a ver la transformación que ha sufrido el personaje. Ha sufrido un proceso de ascesis que le ha llevado a una evolución interna hasta convertirse en una persona con unos principios morales diferentes a los de Dudley. Los nombres dados por O'Connor no son gratuitos: Dudley etimológicamente significa fuerte como un oso, una persona corpulenta. $\mathrm{Al}$ atribuírsele a una persona mayor no hay que quedarse en una 
lectura física, la acepción que consideraremos se refiere a aquel que permanece firme en sus principios. En el caso de Dudley, esos principios se han convertido en prejuicios que le han llevado a ser una persona intransigente, incluso brusca, el sentido del deber lo vive de tal manera que provoca la destrucción del personaje. El nombre de Tanner hace referencia al trabajo de un curtidor, paciente, que toma las pieles, las moldea y le da un aspecto nuevo. Se adapta al cambio sin olvidar la tradición. La intencionalidad de la autora queda patente con el cambio del nombre en los dos protagonistas.

Un año antes de que escribiera este relato, O’Connor había pronunciado una conferencia en la Universidad de Georgetown que se publicó en la revista de la ciudad en 1966 bajo el título de: El novelista católico en el sur protestante (2007: 196). Entre las ideas que recoge, menciona que se está viviendo en una época que se desprecian los valores del viejo Sur y se sustituyen por los del nuevo sin tener en cuenta lo bueno que existía en los estados sureños. En vez de recoger lo valioso de la tradición, se arrasa con ello simplemente porque pertenecía a otra época. Haciendo tabla rasa se corre el riesgo de enfrentarnos con situaciones como las que se describen en el relato.

Tanner se había marchado a vivir con su hija a Nueva York y, de nuevo, su única obsesión es regresar a su viejo hogar, aunque fuera para ser enterrado allí. Tanto es así que obliga a su hija a que le prometa que si fallece volverá a Georgia para descansar en su tierra. En su pueblo, vive su amigo negro Coleman al que le pide que se cumpla su última voluntad cuando llegue el momento porque no confía en que su hija lo haga. De nuevo la relación entre el padre y la hija es fría, distante, en consonancia con el apartamento neoyorkino en el que viven. La hija actúa exactamente por los mismos motivos que en el primer relato: "La compañía de su padre le parecía aburrida y su obligación para con él le pesaba [...] habría tenido la satisfacción de haber intentado cumplir con su deber" (O'Connor, 2006: 823). Con Coleman, pese a que era negro, se había trabado una amistad, incluso compartían techo y aficiones. Aun así, Tanner reconoce que existe una importante diferencia por cuestión racial. De nuevo surge el acontecimiento y en este caso sí se consigue una evolución en el personaje. Todo pasa porque en el edificio, uno de los vecinos es también negro. Esta vez Tanner cree descubrir la oportunidad de trabar una auténtica amistad con esta persona, no tiene en cuenta la diferencia de raza entre ellos. Cree que puede entablar una relación fundada en el respeto que permita un vínculo relacional con independencia del color de la piel. Dudley, ahora Tanner, en el final de sus días ha descubierto el sentido de la vida: el ser humano, social por naturaleza, precisa de la relación con los demás en todo momento, cada día nos hacemos con los otros. 
Nuestra escritora, no deja de sorprender y cuando parece que el desenlace será más halagüeño que en El geranio, se produce el giro flanneriano. En todo encuentro relacional se precisa la convergencia de dos libertades, esta vez Tanner quiere dar el paso, pero el vecino negro no. Es la crítica mordaz de O'Connor hacia la sociedad neoyorkina tan solo dos décadas después de su primer relato: la sociedad ha cambiado sustancialmente, cabe preguntarse si para bien.

El primer encuentro entre Tanner y el vecino discurre con una gran tensión, el anciano es despreciado sin miramientos en el rellano de la escalera y este se queda asombrado ante lo que sucede: su hija vive en el mismo edificio que una pareja de negros y a él le miran con una actitud despectiva. Cuando se lo cuenta, ella le recomienda que les deje en paz, es la única manera de no meterse en problemas y que el mundo vaya bien. O'Connor plantea una importante cuestión: el individualismo social, la forma de convivir es posible si las personas se aíslan y se separan de las demás evitando la confrontación y el problema. Pero parece que esa teoría conduce a las personas a la incomprensión, la soledad y la destrucción. Ante la advertencia de la hija, Tanner contesta: "-Yo me llevaba bien con los negros antes de que tú vinieras al mundo.” (O’Connor, 2006: 825). Es aquí cuando Flannery pone de manifiesto un hecho olvidado a veces por la historia: los sureños habían comprendido que la xenofobia no conducía a nada más que a la destrucción, el odio injustificado al otro por el color de su piel no era admisible. Tanner ya lo había descubierto y no estaba dispuesto a dejar pasar la oportunidad de acercarse a su vecino. Si el Sur había aprendido que la convivencia entre las diferentes razas era posible (O’Connor, 2004: 163), Tanner no cometerá los errores del pasado, reconocerá al otro en su dignidad, ontológicamente todos somos iguales. Su esperanza tenía sentido, la amistad entre un pobre anciano del Sur con un joven neoyorkino negro era posible.

Este cambio de mentalidad en Tanner, la nueva forma de entender el mundo, le provoca la necesidad de mejorar también en la relación que más le importa, la de su hija: "Se sintió culpable. Había sido buena con él y él no había sido más que un estorbo [...] No está mal tu casa, y esta parte del país tampoco está mal. Siento haberte dado tantas molestias al ponerme enfermo" (O’Connor, 2006: 830). Su hija ante esta declaración, le confiesa lo feliz que es por tenerle cerca. Una vez que el vínculo paterno filial se establece, Tanner experimenta la necesidad de mostrarle a Coleman su agradecimiento por todo lo compartido en el pueblo. Decide salir de la casa y regresar a su tierra, había mejorado la relación con su hija, ahora era momento de regresar con su amigo. Cuando salió a las escaleras, empezó a delirar e imaginó su llegada a la estación de su pueblo y el encuentro con los suyos, sin embargo, no era Coleman el que estaba en el 
rellano, era el vecino y su novia que no daba crédito a la imagen de aquel viejo decrépito que gritaba diciendo algo sobre el día del Juicio Final. Tanner se cae al suelo y pide ayuda al neoyorkino para que le levante, pero lo que nos narra O'Connor es desgarrador: su hija regresa al hogar y encuentra el cadáver de su padre empotrado en la barandilla de la escalera. Final abrupto, pero en la intencionalidad de O'Connor no se trata de un desenlace dramático. Aunque el protagonista fallece, la escritora lo deja claro: muere en paz. Ahora el calvario empieza para los otros: el vecino que no solo no ayuda a Tanner, sino que le empotra en las escaleras, hecho que pudo acelerar su muerte; y, su hija, que entierra a su padre en Nueva York en vez de en el pueblo. Del vecino negro no sabemos más. Su hija, dado que no puede descansar, decide desenterrar el cuerpo y mandarlo para su casa, a lo mejor para ella no estaba todo perdido. El estilo del relato es puramente flanneriano, la forma dura e irónica, el fondo esperanzador al menos para Tanner.

En los relatos hemos podido analizar la evolución de Dudley a Tanner, centrémonos en la figura del vecino dentro del contexto social.

Los hijos de los agricultores sureños que habían emigrado al Norte llevan cuatro décadas establecidos en las áreas urbanas norteñas. Han olvidado la mentalidad de sus abuelos y padres para integrarse en el ambiente neoyorkino. Los conflictos raciales, por lo menos en las zonas más cosmopolitas dicen estar superados. Digno de alabar que los prejuicios de sus mayores se habían visto superados, pero olvidar cómo fue posible la paz y la unión entre la población blanca y negra en el Sur era toda una enseñanza que debía rescatarse y, sin embargo, no se hizo. Para liberarse de lo que ellos creían que era el lastre de la Historia, decidieron romper radicalmente con la tradición y hacer tabla rasa de todo lo anterior.

Los más jóvenes, grupo al que pertenecería el vecino negro de Tanner, encabezan el fenómeno conocido como la contracultura. Un movimiento que busca la revolución en las normas sociales y pretenden romper con cualquier estructura que pueda ser identificada con una época anterior. $\mathrm{Al}$ ver a Tanner, lo identifica con un viejo sureño anclado en sus prejuicios raciales. Resulta paradójico que precisamente Tanner sea el que está dispuesto a adaptarse y dejar de lado sus terquedades en vez del joven. El vecino reacciona pero, con una desviación extrema de las normas más básicas de convivencia: no ayuda al anciano cuando este necesita que le coja la mano, es más, le empotra en los barrotes para que no le moleste.

Primer y último relato de O'Connor, dos décadas de diferencia, dos mayores que se ven obligados a dejar su hogar en el pueblo para ir a Nueva York. El mismo planteamiento y, sin embargo, el último relato se ofrece como una segunda oportunidad para que Dudley, ahora rebautizado como Tanner pueda reconsiderar su decisión: abrirse o no al otro. Él lo consigue, 
pero se encuentra con la hostilidad de los nuevos tiempos. La sociedad neoyorkina y parte de los Estados Unidos comenzaba a despertar de la pesadilla racial, recordemos que Martin Luther King pronunció su famoso discurso I have a dream el 28 de agosto de 1963, el relato está escrito un año después. Cierto es que todavía quedaba mucho por construir, pero la convivencia había dado un giro muy favorable en este tema. En cambio, la escritora anticipa la cuestión que estamos analizando: la soledad de los mayores. En un mundo que se mueve a un ritmo frenético, parece no tener cabida. La sociedad utilitarista y, a la par, individualista parece no tener espacio para ellos. En vez de xenofobia empezamos a vislumbrar la gerontofobia, una actitud irracional que provoca actitudes incluso amorales contra los mayores.

3. DUDLEY Y TANNER A LA LUZ DE LA TEORÍA DEL DESARROLLO PSICOSOCIAL DE ERIK ERIKSON

Queremos en este apartado estudiar los dos personajes presentados por O'Connor a la luz de las teorías del desarrollo psicosocial de Erikson. Erik identifica ocho etapas fundamentales en la evolución del individuo, aunque discípulo de Freud, disiente en la relevancia que este último da al desarrollo sexual para explicar el desarrollo evolutivo del individuo. Considera que es más determinante la forma que interactúa el sujeto con la sociedad cada vez que van transcurriendo las distintas etapas de la vida. Para Erikson el paso de un estadio a otro conlleva un proceso progresivo de cambio o de estancamiento, el espacio intermedio en el que se consigue o no la adaptación se define como crisis (2000: 69).

Dudley y Tanner se encuentran en la última etapa de la vida, definida por el autor como: integridad del yo frente a la desesperación. En ella se engloban las personas con una edad superior a los sesenta años. Cuando O'Connor escribe los relatos, plantea con exactitud el momento que están viviendo los protagonistas: dejan de ser productivos en términos económicos, por su edad y estado de salud, y ya no pueden seguir cultivando sus tierras. La forma que tenían tradicionalmente de vivir se va a ver totalmente alterada. A la inactividad laboral hay que sumarle los duelos por la pérdida de los familiares y amigos, los dos han enviudado. Sus hijos no viven en el campo sino emigraron a la ciudad, surge la pregunta: ¿ahora qué? Erikson desarrolla dos actitudes, la integradora y la desesperanza.

Si la actitud es integradora, se acepta la situación y la propia historia. Este proceso es factible en la medida que se puede reconocer la contribución de la propia vida al resto de la sociedad, una persona que con orgullo $\mathrm{y}$, a la par, con honestidad sabe valorar los logros de su trayectoria y su significado para el resto. El apoyo de las personas que rodean al mayor es 
fundamental. Esta situación permite seguir manteniendo una confianza en el propio ser y en los demás, especialmente en las nuevas generaciones. Y, además, se ofrecerá como ejemplo de experiencia y de saber hacer hasta el último momento (Erikson, 1994: 543). Incluso alcanzan una actitud que les permite mantener una serenidad ante la muerte (Bordignon, 2005: 58).

$\mathrm{Si}$, por el contrario, el mayor se encuentra en una situación de desesperanza todo se vuelve contra el sujeto. Erik presenta una clave para no caer en esta pérdida de sentido ante la vida: reconocerse sabios. La sabiduría es la fuerza básica a la que debe recurrir la persona. El ser humano ha acumulado un saber, una capacidad de enjuiciar madura y justamente la realidad que le permite comprender los significados vitales: podrá recordar experiencias vividas que sirvan de espejo al resto ante escenarios semejantes. No es una realidad que venga solo con el pasar de los años (Kunzman, 2019: 355-371) sino afrontar la vulnerabilidad desde la sabiduría de la síntesis existencial que nos invita a reconocernos sujetos y a la apertura y confianza en la libertad del otro (Erikson, 1994: 544). No es el temor a la muerte el que apaga la vida sino la fuerza distónica del desdén y cuyo origen está en la desesperanza. Ya Cicerón nos recordaba que los cimientos de la vejez no son los años, sino que "es la vida anterior vivida con honestidad la que toma los últimos frutos del prestigio" (2013: 93).

O'Connor nos muestra un Dudley débil que teme a la muerte, pero a la par su vida es desesperanza y sufrimiento. Tanner, por el contrario, evoluciona y aprovecha la segunda oportunidad que le ofrece O'Connor. Está dispuesto a ofrecer su experiencia, confiesa a su hija el amor que la tiene y se ve con fuerzas de recuperar su independencia e ir a ver a Coleman, al menos para confesarle que es verdaderamente su amigo. El drama surge porque ante esta postura decidida y sabia surge la incomprensión de una sociedad que no sabe valorar a las personas simplemente porque se encuentran al final del recorrido vital. No es posible la armonía, no es posible que los mayores muestren su saber si el resto del mundo les vuelve la espalda con aires de suficiencia y se dirige a ellos con aire despectivo diciendo: ¿y vosotros qué sabéis? No entendéis nada, este ya no es vuestro mundo. En ese momento, la experiencia del mayor queda excluida y con ello todo su ser.

Sin embargo, no hay que olvidar que, en la síntesis de la vida, queda la mirada feliz del que contempla el mundo, la realidad con un sentido de plenitud e incluso sacralidad. Bordignon siguiendo a Erikson dirá: "Todo muestra una forma trascendente de ser, sentir y considerar el pasado y el presente, porque un futuro nuevo se presenta. No vivido aún, mas sentido por el significado encontrado en la historia de la vida" (2005: 59). Un significado que se le ofrece a la sociedad para que herede parte de la sabiduría acumulada, y que lleva a O'Connor a denunciar a la sociedad que no quiere 
recoger el testigo. La crisis personal que vive Tanner y que se transforma en una oportunidad para no ser otro Dudley, queda restringida a él y a su hija que sabe entender al final del relato los logros de su padre, pero la sociedad no acierta a entenderlo. La esperanza de Tanner y de la hija no se traslada a un mundo que vuelve la espalda a sus mayores. La resolución de la crisis en el protagonista generó confianza y esperanza para poder salir de la soledad, sin embargo, O'Connor presenta un mundo que se asoma al abismo.

Erikson afirma que la resolución positiva de la crisis está ligada no solo con el sujeto que la experimenta sino con el resto (1994: 550). El ser humano adquirirá la capacidad de establecer relaciones positivas con otros miembros de su familia, sobre todo en las etapas 1, 2 y 3; con otros grupos sociales y de trabajo en los estadios 4 a 6 y con el resto de la sociedad e, incluso, con la humanidad en su conjunto en las etapas 7 y 8 (Bordignon, 2005: 60). Dudley no fue capaz de solventar la crisis. Tanner, resuelve positivamente la suya, probablemente en otros momentos no lo hizo, de ahí la situación anquilosada inicial que vive con su hija, pero una vez resuelta consigue trasladar los efectos a la relación paterno filial. Por el contrario, la sociedad egoísta se cierra en un individualismo que no deja cabida para construir relaciones de cooperación, participación e integración. El tabú racial estaba empezando a desaparecer, pero se estaba consolidando un rechazo hacia todo aquello que puede recordar el final de la existencia, un rechazo hacia nuestros mayores.

O'Connor denunciaba esto en sus relatos. Erikson con su teoría sobre el ciclo de la vida pretende proponer a toda sociedad que, si el ser humano es capaz de ir superando las crisis evolutivas a nivel particular, este modelo es posible extrapolarlo al mundo y generar una convivencia más plena en las diversas culturas. El problema es que la eficacia de la teoría depende de la calidad de las personas y de la sociedad de cada tiempo, y por lo que parece el mundo actual apuesta por un tipo de relaciones en el que la resolución de los conflictos no sigue las leyes de la dialéctica, más bien, las de la confrontación.

\section{DUDLEY Y TANNER A LA LUZ DEL MÉTODO DIALÉCTICO DE ROMANO GUARDINI}

Como hemos comentado, la influencia de Romano Guardini en la obra de Flannery O’Connor es manifiesta. En este artículo, queremos analizar el pensamiento del filósofo en lo referente a las etapas de la vida y la relación con la evolución del personaje de Dudley cuando O’Connor lo transforma en Tanner. 
En 1953, Guardini publica Las etapas de la vida: su importancia para la ética y la pedagogía con el que pretende mostrar la importancia de buscar el bien en todas las etapas de la existencia, sin importar la edad. López Quintás, en el prólogo, analiza las claves de comprensión de la obra (2015: 521): en esta búsqueda influye la disposición biológica de la persona, su psique, el entorno que le rodea, la sociedad... todo ello pueden ser factores que jueguen a favor, pero también en contra. Para el hombre son vitales las relaciones que entabla, pues solo con los demás es posible el desarrollo de la persona: "El valor de la existencia humana radica en su capacidad de crear vínculos, establecer relaciones de amistad, ámbitos de convivencia" (2015: 16). Este planteamiento del desarrollo del individuo ligado no solo a su propia madurez sino a las relaciones que establece con los otros se asemeja al planteamiento de Erikson. Si bien, la perspectiva de partida en Guardini responde a reconocerse el ser humano criatura y, por tanto, dependiente desde su misma creación de otro: "Hay que aceptar la propia vida como un don que se nos otorga en el origen y como un obsequio que debemos hacer gustosamente, al final, a Quien nos la dio" (2015: 16). Dudley henchido de orgullo no quiere reconocer la necesidad que tiene de los demás, ni de familia ni de amigos ni de nadie; suple la carencia del vínculo con un geranio.

Guardini describe la edad senil como la etapa donde se alcanza la culminación de la vida, como todo proceso se llegará a ella en función de cómo el hombre se haya preparado para ese estadio. El hombre puede desmoronarse y pensar en lo vacío del existir humano que culmina su paso por este mundo con dolor, sufrimiento y muerte; o, bien, prepararse para el acontecimiento singular, corolario de la vida terrena y que posibilita a la persona para el encuentro con el Creador (2015: 8). Es cierto que esta segunda actitud de apertura es posible en una persona creyente, aunque el propio autor matiza, que no es necesario abrazar una fe concreta para tener una visión esperanzadora que trascienda la vida terrena. Si bien el mismo Guardini apunta que, alguien que pueda abrirse a lo eterno esperando el encuentro definitivo con el Dios Padre, acoge la etapa senil con una felicidad diferente al que no logra trascender el aquí y ahora (2015: 16).

Guardini describe el tramo final de la vida bajo el título La entrada en la ancianidad y lo primero que hace es mostrar una contradicción de su época: describe que hay ancianos que emanan tranquilidad y viven esta etapa con una dignidad admirable, conscientes de que se acercan a la consumación de su tarea; esta actitud parece ser vista por la sociedad como algo poco entendible pues entra en conflicto con lo que se puede considerar una vida digna - aquella que permite al hombre vivir por sus propios medios, de forma autosuficiente y sin depender de nadie- (2015: 101). 
Estas formas de vida seniles son un escándalo para la mentalidad contemporánea occidental. O'Connor lo denuncia con su último relato, aunque la escritora en muchas ocasiones recurre a personas mayores para introducir sus temas, es en este último cuento cuando recrimina a un mundo que ha perdido su sensibilidad ante los mayores, un mundo que concibe esta etapa vital como un estadio que no merece la pena ser vivido, muebles viejos y rotos que se amontonan en los rellanos de las escaleras hasta que se los lleven.

La americana con voz profética denuncia los comienzos de algo que en nuestro siglo XXI se ha convertido en el gran escándalo: las condiciones de precariedad que asfixian a los mayores. El empobrecimiento por la desigualdad entre la inflación de productos y servicios básicos con sus pensiones; la soledad a la que se enfrentan por la dificultad de los hijos de conciliar el cuidado de sus mayores y su trabajo; una pirámide poblacional invertida, cada vez de forma más notoria, que reduce la posibilidad de dedicar partidas de gasto público a paliar sus necesidades... y, mientras tanto, son más y más las noticias que cubren las páginas de los periódicos con datos de mayores que aparecen muertos en sus casas y, se encuentran sus cadáveres pasados días, gracias a algún vecino que da la voz de alarma por el olor que se desprende de la casa.

Guardini también denunciaba que la sociedad consideraba la etapa senil como el momento de destrucción de la persona, en vez de entenderla como la culminación de la vida (López Quintás, 2001: 87). Y advierte que, si la sociedad cree que los mayores no pueden aportar a este mundo, no es de extrañar que el anciano se repliegue en una obstinación senil, "se interesa menos por lo nuevo. Cuanto mayor se hace, menos llevada se siente a cambiar las cosas, sino que lo que quiere es que le dejen tranquila. Se cierra a cualquier interés por la vida colectiva" (Guardini, 2015: 103) y de ahí la apuesta por vivir postrado contemplando un decrépito geranio. Dudley no anhela ganarse la estima y simpatía de otras personas, ni de su hija ni del vecino, vivirá replegado en su butaca esperando la muerte. Si no se genera un ámbito de relación con el otro, el ser humano queda condenado a la soledad y a la muerte. Pero para crear un vínculo es preciso la conjunción de dos voluntades: el yo y el tú que se abrazan para formar un nosotros (López Quintás, 2009: 227). En este caso, la obstinación de Dudley impide el acercamiento del vecino y se precipita a una espera estéril, sentado con la vista perdida en un alfeizar vacío.

Por el contrario, Guardini advierte que otra forma de vivir la senilidad es posible. Todos somos testigos de personas que se enfrentan a este momento vital desde una tranquilidad amable: "Ocupan con total naturalidad el lugar que les corresponde en su entorno, y su experiencia de la vida les permite resolver más de una dificultad sin llamar la atención” (2015: 107). 
La experiencia y el recorrido que han alcanzado les enseña a comprender a las demás personas y a respetarlas. La vejez reclama ser vivida desde la serenidad de que el final de la vida sigue siendo vida. Desde esta mirada podemos alcanzar satisfacciones que solo son posibles en ese momento, capaces de distanciarnos de las cosas y abrirnos a la esencia de la vida (Guardini, 1999: 479).

Tanner entendió el paradigma de una nueva época en la que los negros y los blancos podían convivir bajo un mismo techo, enamorarse, formar familias... Pero cabe dejarse interpelar y decir para qué le sirvió a Dudley cambiar y convertirse en Tanner. Esta vez la comunión de voluntades no había sido posible porque en el avance social de las dos últimas décadas se había perdido parte de los valores que permitían una convivencia entre las distintas generaciones. Ahora el ritmo del mundo excluía a todos aquellos que no podían sumarse a los engranajes de un progreso utilitarista y deshumanizado. A Tanner, esta mentalidad encarnada en su vecino, le costó la vida, había fallecido levantando su mano en señal de socorro y no consiguió la ayuda requerida. En la siguiente escena, Tanner yace muerto entre los barrotes de las escaleras.

Guardini entiende que en nuestro mundo todo aquello que puede recordar el dolor, el sufrimiento y la muerte hay que apartarlo del día a día. Es como si al alejarlo de nuestra cotidianidad pudiéramos evitar el fatídico desenlace. El filósofo comenta que "para la conciencia actual la muerte carece de todo acento valorativo positivo" (2015: 110). Morir es algo tan peyorativo que causa terror, de ahí que se intente apartarla de nuestra vida para no tomar conciencia de ella y seguir como si esta no nos esperara al final del camino. Los mayores nos recuerdan la proximidad del final de la existencia por ello nos duele mirarlos a los ojos. Al hombre actual le cuesta tomar conciencia de su propio final tal vez por no sentirse satisfecho al contemplar su trayectoria vital.

Desde la perspectiva flanneriana y del mismo Guardini, el dolor, el sufrimiento y el tener conciencia de la muerte puede tener un sentido salvífico para el hombre. La producción literaria de O'Connor y sus cartas recogen la idea de que la sociedad actual parece necesitar el sufrimiento para alcanzar la salvación, la gracia que se le ofrece al hombre cuesta. Así en una de sus epístolas escritas en 1960 podemos leer: "Su idea de que la gracia es sanadora omite el hecho de que, antes de sanar, corta con la espada que Cristo dijo que iba a traer" (2004: 411). Guardini ante el sufrimiento, en el mismo sentido que Flannery, dirá: "el dolor puede ser una puerta abierta a Dios, una forma de purificación" (1954: 93). El acontecimiento transformador en Tanner habría tenido sentido para él y su hija, ahora es cosa de la sociedad que sepa recapacitar sobre la deriva de lo que está sucediendo, tal vez no sea tarde para el cambio. 


\section{CONCLUSIONES}

En el presente artículo hemos querido dialogar con una literata, un psicólogo social y un filósofo. Personas de diferentes disciplinas que tuvieron la sensibilidad a través de su vocación de referirnos la realidad del mundo en el que vivían. A la par, como si de una voz profética se tratara, se anticiparon a los problemas que podían aparecer en las generaciones futuras si la sociedad no reconsideraba determinados aspectos. Hemos querido llamar la atención sobre nuestros mayores. La esperanza de vida ha aumentado en las últimas décadas, con la última crisis económica han sido piezas fundamentales para sostener a las familias y, sin embargo, son apartados de nuestras vidas cuando entendemos que dejan de ser útiles.

Se les ha pedido que se adapten a los tiempos, que cuiden de los nietos, que aprendan a utilizar los smartphones y cuando lo han hecho y se han subido al tren del progreso, les hemos apeado en la siguiente parada. En una sociedad que la ética de la muerte parece clavar sus garras cada vez con más fuerza, pasarán a ser los excluidos del sistema.

De nada parece servir que Erikson dignifique la octava etapa de la vida y Guardini muestre los valores que se pueden alcanzar en la edad senil y ofrecerlos a las próximas generaciones. La puerta se les cierra. Les aparcamos en los nuevos jardines de infancia para mayores porque nuestro día a día nos impide dedicarles nuestro tiempo. Y por si esto no es suficiente, algunos países apuestan por una serie de leyes que dignifiquen el final de la vida, haciendo uso de eufemismos en el leguaje. Y piden una muerte rápida e higiénica, la nueva eugenesia bajo la expresión derecho a una muerte digna, muestra la atrocidad de un mundo que no es capaz de reconocer la auténtica dignidad del hombre.

O'Connor, Erikson y Guardini reconocieron la deriva social y la denunciaron en sus obras, a nosotros nos queda la posibilidad de reconsiderar su herencia u obviarla.

\section{REFERENCIAS}

Álvarez, M.A. (1992). Lugar preferente de la novela corta en la literatura norteamericana. Epos. Revista de Filosofía, 8, 415-433.

Arbona, G. (2006). Prólogo. En F. O’Connor, Un encuentro tardío con el enemigo. Madrid: Ediciones Encuentro.

Bordignon, N. A. (2005). El desarrollo psicosocial de Erik Erikson: El diagrama epigénetico del adulto. Revista Lasallista de Investigación, 02 (02), 50-63.

Broncano, M. (1992). Mundos breves, mundos infinitos: Flannery O'Connor y el cuento norteamericano. León: Universidad de León, Secretariado de Publicaciones. 
Cicerón, M. T. (2013). Sobre la vejez; Sobre la amistad. (M. E. Torrego Salcedo, Trad.). Madrid: Alianza Editorial.

Erikson, E. H. (1994). Un modo de ver las cosas: Escritos selectos de 1930 a 1980. (J. J. Utrilla, Trad.). México D.F.: Fondo de Cultura Económica.

Erikson, E. H. (2000). El ciclo vital completado. (R. Sarro Maluquer, Trad.). Barcelona: Paidós.

Guardini, R. (1954). El Señor. (F. Palau-Ribes Casamitjana, Trad.). Madrid: Rialp.

Guardini, R. (1999). Ética: Lecciones de la Universidad de Múnich. (C. Romero \& C. Díaz, Trad.). Madrid: Biblioteca de Autores Cristianos.

Guardini, R. (2015). Las etapas de la vida: Su importancia para la ética y la pedagogía. (J. Mardomingo, Trad.). Madrid: Palabra.

Kunzman, U. (2019). Wisdom: The Royal Road to Personality Growth. En R. Fernández Ballesteros, A. Benetos \& J.-M. Robine (Ed.), The Cambridge handbook of successful aging (pp. 355-371). New York, NY: Cambridge University Press.

Lancelotti, M. (1965). De Poe a Kafka: para una teoría del cuento. Buenos Aires: Editorial Universitaria.

López Quintás, A. (2001). La verdadera imagen de Romano Guardini: Ética y desarrollo personal. Pamplona: Ediciones Universidad de Navarra.

López Quintás, A. (2009). La antropología relacional de Romano Guardini. Veritas. Revista de Filosofía y Teología, (21), 219-244.

López Quintás, A. (2015). Prólogo. En R. Guardini, Las etapas de la vida: Su importancia para la ética y la pedagogía (pp. 5-21). Madrid: Palabra.

O’Connor, F. (2004). El hábito de ser. Cartas seleccionadas y editadas por Sally Fitżgerald. (J. Molina de la Torre, Trad.). Salamanca: Sígueme.

O’Connor, F. (2006). Cuentos completos. (M. Covián, C. Filipetto \& V. Ozores, Trad.). Barcelona: Lumen.

O’Connor, F. (2007). Misterio y maneras: Prosa ocasional escogida y editada por Sally y Robert Fitzgerald. (E. Navío \& G. Arbona Abascal, Trad.). Madrid: Encuentro.

Sagredo Santos, A. (t.y.). Crisis agraria y éxodo rural en estados unidos en el primer tercio del siglo XX y la legislación reformista del New Deal. REDEN: Revista Española de Estudios Norteamericanos, 21-22, 75-87.

Scott, R. N. \& Streight, I. H. (Ed.) (2009). Flannery O'Connor: The contemporary reviews. Cambridge: Cambridge University Press. 